\title{
Consequences of Stenting and Endoscopic Papillary Balloon Dilatation in Treatment of Large and Multiple Common Bile Duct Stones
}

\author{
Ahmad Hormati 1,2, Mohammad Reza Ghadir ${ }^{3}$, Ali Hasanpour Dehkordi ${ }^{4}$, Farshad Yadollahi 5 \\ Shahriar Salehitali6, ${ }^{6}$, Mahboobeh Afifian ${ }^{7}$
}

1. Assistant Professor, Gastroenterology and Hepatology Disease Research Center, Qom University of Medical Sciences, Shahid Beheshti Hospital, Qom, Iran.

2. Assistant Professor, Gastrointestinal and Liver Disease Research Center, Iran University of Medical Sciences, Firoozgar Hospital, Tehran, Iran

3. Professor, Gastroenterology and Hepatology Disease Research Center, Qom University of Medical Sciences, Shahid Beheshti Hospital, Qom, Iran

4. Associate Professor, School of Allied Medical Sciences, Shahrekord, University of Medical Sciences, Shahrekord, Iran .

5. Medical Resident, Medical College, Shahrekord University of Medical Sciences, Shahrekord, Iran

6. Assistant Professor, School of Nursing and Midwifery, Shahrekord University of Medical Sciences, Shahrekord, Iran

7. MSc of Health Information Technology of Tehran University of Medical Sciences, Tehran, Iran

\footnotetext{
* Corresponding Author:

Shahriar Salehitali, MD

School of Nursing and Midwifery, Shahrekord University of Medical Sciences, Shahrekord, Iran.

Telefax: + 9838033335654

Email: sh_salehitali@yahoo.com

Received: 10 Jun. 2019

Accepted: 01 Sep. 2019
}

\section{ABSTRACT}

\section{BACKGROUND}

Although stenting for the treatment of large and multiple common bile duct stones has been acceptable to everyone, its efficacy and outcome have not been studied in comparison with other endoscopic procedures. The purpose of this study was to compare the consequences of stenting and endoscopic papilla balloon dilatation for the treatment of large and multiple common bile duct stones.

\section{METHODS}

In a double-blind clinical trial, of 431 patients with bile duct stones referred to the treatment center, 64 patients with multiple common bile duct stones $(\geq 3)$ and more than $15 \mathrm{~cm}$ were selected for the study, then by random allocation rule the participants were allocated in two groups. They were entered into two different endoscopic papillary balloon dilatation (EPBD) and common bile ducts stenting treatments so that both procedures were performed by a person. Both groups were assessed from the point of views therapeutic outcomes such as duct cleaning, pancreatitis, isolated pain, and duct rupture. Data were collected by a self-made questionnaire that was used before and after the procedure to obtain the needed information. Then data were analyzed using SPSS software version 22 and descriptive and analytical tests were used as appropriated.

\section{RESULTS}

Although the duct cleaning and the complete removal of the stones in the stenting treatment procedure was $93.8 \%$, and in EPBD was $78.3 \%$, no significant difference was observed between the two groups $(p=0.14)$. Pancreatitis significantly increased after the first and second endoscopic retrograde cholangiopancreatography (ERCP) in the stent group compared with $\mathrm{EPBD}(p=0.02)$. Also, the most frequent cases of isolated pain were in the endoscopic group $\operatorname{EPBD}(p=0.0)$. However, the occurrence of perforation after first ERCP and EPBD was zero, but in the second stage of ERCP, $3.3 \%$ of the patients had perforations $(p=0.99)$. The results indicated that the shape of the stone (circular and angled) was not effective in the result of treatment in the two groups.

\section{CONCLUSION}

The results of this study indicated that in case of experience and skill in conducting the ERCP, common bile duct stenting is still the first line of treatment for large and multiple stones of the common bile ducts.

\section{KEYWORDS:}

CBD Stone, Endoscopic Treatment of EPBD, CBD Stenting, ERCP

Please cite this paper as:

Hormati A, Ghadir MR, Hasanpour dehkordi A, Yadollahi F, Salehitali SH, Afifian M. Consequences of Stenting and Endoscopic Papillary Balloon Dilatation for the Treatment of Large and Multiple Common Bile Duct Stones. Middle East J Dig Dis 2019;11:205-210. doi:10.15171/mejdd.2019.150. 


\section{INTRODUCTION}

$7-12 \%$ of patients undergoing cholecystectomy for the treatment of symptomatic gallstones have common bile duct (CBD) stones. These patients are good candidates for endoscopic retrograde cholangiopancreatography (ERCP). ${ }^{1}$ ERCP with endoscopic sphincterotomy and removing stones by balloons and baskets are commonly used to treat CBD stones, so that, between $85-95 \%$ of all bile duct stones can be effectively treated by these commonly used methods. ${ }^{2,3}$

Difficult access to the biliary duct stones due to the primary diverticulum, sigmoid shape bile duct stone, after billroth, ${ }^{2}$ gastrojejunostomy, a large number of stones, large stone size (above $15 \mathrm{~mm}$ ), non-natural stone location, and abnormally shaped stone cause the treatment process by common endoscopic methods a difficult and challenging one. ${ }^{4-6}$

Although CBD stones with a maximum diameter of $15 \mathrm{~cm}$ can be evicted by endoscopic sphincterotomy, with the increase in stone diameter the chance of evicting a stone dropped so that the stones with a diameter larger than $2 \mathrm{~cm}$ should be broken before leaving the duct. ${ }^{7-9}$

Currently, for the treatment of stones known as complex stones, several methods such as lithotripsy, electro-hydraulic lithotripsy, laser lithotripsy, endoscopic papillary balloon dilatation, sphincterotomy, and stenting are used. ${ }^{8}$ Electrohydraulic lithotripsy (EHL) is associated with increased risk of duct rapture ${ }^{4}$ and endoscopic papillary balloon dilatation is associated with an increased risk of pancreatitis. ${ }^{10}$ Also lithotripsy is not available in all centers and is very expensive.

For elderly patients for whom surgical procedures and endoscopic procedures are harmful, stenting is a very suitable method. ${ }^{11,12}$ The study by Yay and colleagues suggests that stenting is an appropriate and practical way to treat complicated biliary stones in older people. ${ }^{13}$ Also, the results of other studies indicate that stent has been able to help evicting stones from bile ducts by reducing the number and size of stones over a period of 2 months.$^{13}$

Although not timely treatment of common biliary duct stones, as well as their removal, is associated with serious complications such as pancreatitis and cholangitis. The use of procedures with less negative consequences is very important for these patients. The purpose of this study was to compare the success rate and side effects of treatment of large (above $15 \mathrm{~mm}$ ) and multiple (more than 3 stones) CBD stones by stenting process and other endoscopic procedure in the patients with Large and Multiple Common Bile Duct Stones referring to Shahid Beheshti Medical Center affiliated to Qom University of Medical Sciences.

\section{MATERIALS AND METHODS}

The current randomized controlled trial study was conducted on patients with large and multiple common bile duct stones who referred to Shahidbeheshti Teaching Hospital in Qom, Iran. This project was approved by Qom university of medical sciences ethics Committee (IR MUQ.REC.1394.133.) The research project was registered in the Iranian Registry of Clinical Trials (code no. IRCT2017020831252N). In a connivance sampling from 413 patients referred to Shahidbeheshti Teaching Hospital in Qom 64 patients had inclusion criterion (CBD stones larger than $15 \mathrm{~cm}$ and the number of stones $(3 \leq)$. The patients with coagulation disorder and ERCP were excluded from the study. The selected cases were allocated in two groups based on the random allocation rule to receive stenting intervention or endoscopic papillary balloon dilation (EPBD) for removing stones from the duct.

Dilatation balloon was done based on the diameter of CBD and the size of the ampule Water so that dilatation was between 15 to $18 \mathrm{~mm}$ and time between 45 and 60 seconds with the endophex balloon of Germany. Plastic stents with the radius of 10 French and length of 8-12 cm from Endo-flex Company (Germany) were used. Initially, demographic information and data from the imaging study (sonography, and Magnetic Resonance Cholangiopancreatography) including the size, number, and shape of the stone were measured so that the size of the stone was indicated with fluoroscopy by injection of radiocontrast agent in the CBD and seeing the stones with radiographic images during ERCP. Then patient follow-up was assessed from the point of view of the therapeutic outcomes after ERCP, such as duct cleaning, pancreatitis, isolated pain, and duct rupture. It should be noted that in the stenting group, the patients were evaluated in the first stage after the stent and in the second stage for the removal of stones with regard to the therapeutic outcomes. Data were analyzed using SPSS software version 22 and descriptive and analytical tests such as paired t test, independent $t$ test, Chi-square test, and oneway ANOVA were used as appropriated. 
Table 1: Establishment of bile ducts flow in patients with large and multiple common bile duct stones in stenting and endoscopic papillary balloon dilatation groups based on stone shape

\begin{tabular}{lccccccc}
\hline \multirow{2}{*}{$\begin{array}{l}\text { Therapeutic } \\
\text { intervention }\end{array}$} & Stone shape & \multicolumn{4}{c}{ Success in establishing flow in the duct } \\
\cline { 3 - 8 } & & \multicolumn{2}{c}{ Complete success } & \multicolumn{2}{c}{ Relative success } & \multicolumn{2}{c}{ Failure } \\
\cline { 3 - 8 } & & Count & \% & Count & \% & Count & \% \\
\hline \multirow{3}{*}{ Stent } & Angled & 4 & 57.1 & 0 & 0 & 3 & 42.9 \\
& Circular & 21 & 84 & 0 & 0 & 4 & 16 \\
\hline \multirow{3}{*}{ EPBD } & Total & 25 & 78.1 & 0 & 0 & 7 & 21.9 \\
& Angled & 9 & 90 & 0 & 0 & 1 & 10 \\
\hline & Circular & 21 & 95.5 & 1 & 4.5 & 0 & 0 \\
\hline
\end{tabular}

Table 2: The therapeutic outcomes of stenting and endoscopic papillary balloon dilatation groups in patients with large and multiple common biliary duct stones

\begin{tabular}{lcccccccc}
\hline \multirow{2}{*}{ Therapeutic intervention } & \multicolumn{2}{c}{ EPBD } & \multicolumn{2}{c}{ First step CBD stenting } & Second step CBD stenting & P value \\
\cline { 2 - 9 } \multicolumn{1}{c}{ The consequence of intervention } & Count & $\mathbf{\%}$ & Count & $\mathbf{\%}$ & Count & \% & \\
\hline Complete removal of stone & 25 & 78.1 & - & - & 30 & 93.8 & 0.14 \\
\hline Pancreatitis & 2 & 6.2 & 6 & 18.8 & 0 & 0 & 0.025 \\
\hline Cholangitis & 0 & 0 & 0 & 0 & 0 & 0 & 0 \\
\hline Isolated pain & 6 & 18.8 & 1 & 3.1 & 1 & 3.1 & 0.046 \\
\hline Perforation & 0 & 0 & 0 & 0 & 1 & 3.1 & 0.99 \\
\hline
\end{tabular}

\section{RESULTS}

The frequency of women in the stent group was $60 \%$ and in the EPBD group was $40 \%$. The frequency of men in the stent group was $40 \%$ and in the EPBD group was $60 \%$, so that the Chi-square test detected there was no significant difference between the two groups in terms of sex. The mean age of the two groups of stents and EPBD was 32.81 and 32.19 respectively. Mann-Whitney test showed that there was no significant difference between the two groups ( $p=0.893)$.

There were no statistically significant differences between the two intervention groups in terms of diameter and number of stones in the common ducts. The mean diameter of the stones in stent and EPBD group was $17.4 \pm$ 2.86 and $37.17 \pm 2.19 \mathrm{~mm}$, respectively $(p=0.96)$.

The mean and standard deviation of the number of stones in the stenting group was $3.31 \pm 1.32$ and in the endoscopic treatment of EPBD was $2.99 \pm 1.247 . p=0.075$ indicated that there was no significant difference between the two groups.

The rate of success of stone removal from the duct in terms of stone shape in the two groups of stents and EPBD did not have statistically significant difference (table 1).
The results indicated that the therapeutic outcomes, in the two groups of stenting and EPBD treatment, were not significantly different in many dimensions (table 2).

Based on the Mantel-Haenszel test, no meaningful statistical relationship was found between the stone shape and the success rate $(p=0.12)$. The results detected that in the stent group, there was no specific complication but the complication was related to the ERCP.

\section{DISCUSSION}

The purpose of this study was to compare the success rate and side effects of large (above $15 \mathrm{~mm}$ ) and multiple (more than 3 stones) CBD stones treatment by stenting process and other endoscopic procedure in the patients referring to Shahid Beheshti Medical Center affiliated to Qom University of Medical Sciences.

The results indicate that the frequency of successful removal of large and multiple stones was $94 \%$ and $78 \%$ $\&$ respectively by stenting and $78 \%$ endoscopic papillary balloon dilatation. Although there was no statistically significant difference between the two groups, the success rate of the removal of large and multiple stones 
and ultimately the complete opening of the duct has been more successful by stenting than endoscopic papillary balloon dilatation.

In the study by Horiuchi the success rate of removal of stones was $93 \%,{ }^{14}$ the HUNG study indicates the success rate of removal of stone as $94 \%$. In the study by Hui, the success rate of removal of stone was $94.7 \%,{ }^{14}$ and in the study by YE, the success rate of removal of stone was $94.1 \%$. These results confirm the results of the current study. ${ }^{15}$

Although this rate was significantly reduced in the study of ASLAN and colleagues, only $62.5 \%$ of the patients had experienced a successful removal of stone by baskets, which was due to the fact that patients were not first treated with baskets, but the previous treatment procedures had not been successful. ${ }^{16}$

In a comparative study conducted by Hoye and coworkers, the degree of duct clearing in electrohydraulic lithotripsy was $76.5 \%$ and $94.7 \%$ in the stent method. The result of this study is consistent with the current study and reflects the fact that stenting is the first line of treatment in the successful clearing of CBD stones. ${ }^{17}$ Jane Sca and colleagues concluded that 6 months after stenting, removal of big stone from bile ducts, was very significant in most patients. $^{18}$

Di Giorgio P and co-workers in their study concluded that stenting was a simple and safe method for managing large and multiple stones, while many of these patients were not suitable for surgical procedures or are at high risk. ${ }^{19}$

Chiro Yasuda1 and Takao Iota, in their study, conclude that although there are various methods for treating biliary stones, endoscopic sphincterotomy can be done with balloon or first-line catheter reabsorption of bile ducts. ${ }^{5}$ Chan AC, in the conclusion of his study, says that although it is difficult to get out of the duct with the enlargement of the stone, it will be very easy to remove large and multiple stones after stenting. ${ }^{20}$ Also Katsin Loos and co-workers indicate that endoscopy with stenting is one of the best methods for clearing bile ducts in large and difficult stones. ${ }^{21}$

The result of this study indicated that pancreatitis in the treatment with stents in the first and second stages was significant compared with EPBD treatment. So that in the first stage, $18 \%$ of patients, and in the second stage of the stenting, none of the patients had pancreatitis, but about $6 \%$ of the patients had pancreatitis during treatment with EPBD. However, the stent was very successful in removing the entire stone and opening the bile duct, but complications of pancreatitis after the procedure are a threat to patients.

In the Horiuchi study, the incidence of pancreatitis after the first stage of the stent was $5 \%$, and in the Hong study, it was $1.9 \%$. Also in the study by Jagielski and colleagues, it was $5.44 \% .^{14,22,23}$ In a study by Edwina Chan and others, out of 1,000 patients who underwent ERCP and 87 patients after the ERCP, they had unplanned complications in hospital, and $41.1 \%$ of the patients had pancreatitis so that the incidence of pancreatitis in the entire under study population was $3.6 \%{ }^{24}$ The high incidence of pancreatitis in this study can be due to the lack of sufficient experience of operators. Therefore, one of the most important factors in the treatment with stent was the sufficient experience of people working with endoscopic devices, especially the ERCP device..$^{25,26}$

The result of the study shows that the incidence of cholangitis in the two groups was equal to zero percent. In the study of Edwina Chan and colleagues, the incidence of cholangitis was reported to be $3 \%$, while the population surveyed was $1,000 .{ }^{23}$ In the Horiuchi study, the incidence of cholangitis in the first stage of stenting was $13 \%$, and in the Hong study, this rate was reported as 3.8\% after the first stage of stenting. ${ }^{21}$ Differences in the results of the studies indicated that the present study examined the presence of cholangitis in patients during the hospital admission and also 2 weeks after the procedure, while in the Horiuchi study, this rate was 6 months after the procedure. So, the results indicate that following up patients after ERCP in terms of infectious and inflammatory outcomes should not be limited to the short period of time during hospital admission in the ward and just after the procedure, but in a long-term period, patients should be checked in line with complications and possible outcome.

The result of the study showed that the rate of occurrence of isolated pain (single pain without increasing pancreatic enzymes and the absence of evidence based on pancreatitis and cholangitis) in the EPBD group was 18.8, but after the first and second ERCP, it was 3.1\% and 3.1, respectively. There was a significant difference between the two groups in the occurrence of pain after the treatment procedure. This difference can be attributed to the higher pressure exerted on the sphincter during the balloon dilatation for the extraction of large stones. ${ }^{27}$ 
In the study of Edwin and colleagues, although many of the risk factors associated with hospital admission and the side effects of ERCP have been reported but in your conclusion suggested that many patients had severe pain after ERCP not only this pain was not expressed by the patients but also there was not suitable evidence to detected this pain related to one of the complications of the procedure, ${ }^{24} \mathrm{we}$ had this pattern of pain in our patients.

Although perforation has not been occurred in the EPBD group and the first stage of stenting, it was 3.1\% in the second stage of stenting.

In the study of Asad and colleagues, in line with endoscopic management of CBD in a 5-year process from 2011 to 2016, 129 patients with CBD stones, the results showed that in none of the cases treated by ERCP, duct rupture was reported. ${ }^{27}$ While Andrewlee and others in their study concluded that ERCP had severe and moderate complications, and in their review under the title of investigating post-ERCP complications, the rate of perforation in 16885 patients under ERCP from 1977 to 2006, was reported to be $6 \% .{ }^{28}$ Also in the study of Salminin and Lini for assessing post-ERCP complications in 2555 patients, perforation rate was only $0.2 \%$ and in the conclusion part of their study, it was indicated that lethal complications after ERCP were rare in their study. ${ }^{29}$ Kharbutli B, VelanovichV suggest that the exploration of CBD stones by the endoscope has less mortality and morbidity rate. ${ }^{30}$ Thus, in other studies, the low level of perforation and threatening complications was reported very poorly. ${ }^{31}$

\section{CONCLUSION}

Although large and multiple biliary stones could be treated with several endoscopic methods but the stenting method is a selective therapeutic approach with full duct clearance and minimal side effect if the procedure is performed by a person with full experience and skill.

\section{Study limitations:}

The low sample size of this study is due to the low frequency of patients with large and multiple CBD stones. Therefore, researchers believe that more valuable studies with larger sample size is needed to achieve a better result.

\section{ACKNOWLEDGEMENT}

This research was sponsored by the Research and
Technology Deputy of Qum University of Medical Sciences.

\section{ETHICAL APPROVAL}

There is nothing to be declared.

\section{CONFLICT OF INTEREST}

The authors declares no conflict of interest related to this work.

\section{REFERENCES}

1. Freitas ML, Bell RL, Duffy AJ. Choledocholithiasis: evolving standards for diagnosis and management. World J Gastroenterol 2006;12:3162-7. doi: 10.3748/wjg.v12.i20.3162.

2. Strömberg C, Nilsson M. Nationwide study of the treatment of common bile duct stones in Sweden between 1965 and 2009. Br J Surg 2011;98:1766-74. doi: 10.1002/bjs. 7690.

3. Samardzic J, Latic F, Kraljik D, Pitlovic V, Mrkovic H, Miskic D, et al. Treatment of common bile duct stones is the role of ERCP changed in era of minimally invasive surgery? Med Arh 2010;64:187-8.

4. Stefanidis G, Christodoulou C, Manolakopoulos S, Chuttani R. Endoscopic extraction of large common bile duct stones: A review article. World J Gastrointest Endosc 2012;4:167-79. doi: 10.4253/wjge.v4.i5.167.

5. Yasuda I, Itoi T. Recent advances in endoscopic management of difficult bile duct stones. Dig Endosc 2013;25:376-85. doi: 10.1111/den.12118.

6. Sarkeshikian S, Hormati A, Ghadir M, Pezeshki Modares M, Alami F. Relative Prevalence of Duodenal Diverticulum and its Association with Pancreatic Biliary Disease in ERCP Patients. J Adv Med Biomed Res. 2018;26:46-52.

7. Stefanidis G, Christodoulou C, Manolakopoulos S, Chuttani R. Endoscopic extraction of large common bile duct stones: A review article. World $J$ Gastrointest Endosc 2012;4:167-79. doi: 10.4253/wjge.v4.i5.167.

8. Trikudanathan G, Navaneethan U, Parsi MA. Endoscopic management of difficult common bile duct stones. World $J$ Gastroenterol 2013;19:165-73. doi: 10.3748/wjg.v19. i2.165.

9. Lauri A, Horton RC, Davidson BR, Burroughs AK, Dooley JS. Endoscopic extraction of bile duct stones: management related to stone size. Gut 1993;34:1718-21. doi: 10.1136/gut.34.12.1718.

10. Paik WH, Ryu JK, Park JM, Song BJ, Kim J, Park JK, et al. Which Is the Better Treatment for the Removal of Large Biliary Stones? Endoscopic Papillary Large Balloon Dilation versus Endoscopic Sphincterotomy. Gut Liver 2014;8:438-44. doi: 10.5009/gnl.2014.8.4.438.

11. Jin PP, Cheng JF, Liu D, Mei M, Xu ZQ, Sun LM. Endoscopic papillary large balloon dilation vs endoscopic sphincterotomy for retrieval of common bile duct stones: A meta-analysis. World J Gastroenterol 2014;20:554856. doi: 10.3748/wjg.v20.i18.5548. 
12. Park JS, Jeong S, Bang BW, Kang AR, Lee DH. Endoscopic Papillary Large Balloon Dilatation Without Sphincterotomy for the Treatment of Large Common Bile Duct Stone: Long-Term Outcomes at a Single Center. Dig Dis Sci 2016;61:3045-53. doi: 10.1007/s10620016-4220-4.

13. Ye X, Huai J, Sun X. Effectiveness and safety of biliary stenting in the management of difficult common bile duct stones in elderly patients. Turkish J Gastroenterol 2016;27:30-6. doi: 10.5152/tjg.2015.150305.

14. Horiuchi A, Nakayama Y, Kajiyama M, Kato N, Kamijima T, Graham DY, et al. Biliary stenting in the management of large or multiple common bile duct stones. Gastrointest Endosc 2010;71:1200-3.e2. doi: 10.1016/j. gie.2009.12.055.

15. Yang J, Peng J, Chen W. Endoscopic biliary stenting for irretrievable common bile duct stones: Indications, advantages, disadvantages, and follow-up results. Surgeon 2012;10:211-7.

16. Aslan F, Arabul M, Celik M, Alper E, Unsal B. The effect of biliary stenting on difficult common bile duct stones. Prz Gastroenterol 2014;9:109-15. doi: 10.5114/ pg.2014.42507.

17. Hui CK, Lai $\mathrm{KC}, \mathrm{Ng} \mathrm{M}$, Wong WM, Yuen MF, Lam SK, et al. Retained common bile duct stones: a comparison between biliary stenting and complete clearance of stones by electrohydraulic lithotripsy. Aliment Pharmacol Ther 2003;17:289-96. doi: 10.1046/j.13652036.2003.01415.x

18. Jain SK, Stein R, Bhuva M, Goldberg MJ. Pigtail stents: An alternative in the treatment of difficult bile duct stones. Gastrointest Endosc 2000;52:490-3. doi: 10.1067/mge.2000.108409.

19. Di Giorgio P1, Manes G, Grimaldi E, Schettino M, D'Alessandro A, Di Giorgio A, GiannattasioF.Endoscopic plastic stenting for bile duct stones: stent changing on demand or every 3 months. A prospective comparison study. Endoscopy 2013;45:1014-7

20. Chan AC, Ng EK, Chung SC, Lai CW, Lau JY, Sung JJ, et al. Common bile duct stones become smaller after endoscopic biliary stenting. Endoscopy 1998;30:356-9. doi: 10.1055/s-2007-1001282.

21. Katsinelos P, Galanis I, Pilpilidis I, Paroutoglou G, Tsolkas P, Papaziogas B, et al. The effect of indwelling endoprosthesis on stone size or fragmentation after long-term treatment with biliary stenting for large stones. Surg Endosc 2003;17:1552-5. doi: 10.1007/s00464-002-9240-9.

22. Hong WD, Zhu QH, Huang QK. Endoscopic sphincterotomy plus endoprostheses in the treatment of large or multiple common bile duct stones. Dig Endosc 2011;23:240 3. doi: 10.1111/j.1443-1661.2010.01100.x.

23. Jagielski M, Smoczyński M, Jabłońska A, Adrych K. Endoscopic treatment of intraductal pancreatic stent fragmentation. Dig Endosc 2017;29:798-805. doi: 10.1111/ den.12887.
24. Chan E, Neeman T, Thomson A. Follow-up to determine unplanned hospitalization and complications after endoscopic retrograde cholangiopancreatography. ANZ J Surg 2018;88:E142-E146. doi: 10.1111/ans.13799.

25. Sarkeshikian SS, Hormati A. The Incidence Rate of PostERCP Pancreatitis and Its Related Factors. Qom Univ Med Sci J 2017;11:49-56.

26. Hormati A, Sarkeshikian SS, Alemi F, Ghadir MR. PostERCP Pancreatitis With Normal Serum Amylase Level: A Case Report. Govaresh 2018;23:93-7.

27. Salama AF, Abd Ellatif ME, Abd Elaziz H, Magdy A, Rizk H, Basheer M, et al. Preliminary experience with laparoscopic common bile duct exploration. BMC Surg 2017;17:32. doi: 10.1186/s12893-017-0225-y.

28. Andriulli A, Loperfido S, Napolitano G, Niro G, Valvano MR, Spirito F, et al. Incidence rates of post-ERCP complications: a systematic survey of prospective studies. $\mathrm{Am}$ $J$ Gastroenterol 2007;102:1781-8. doi: 10.1111/j.15720241.2007.01279.x.

29. Samardzic J, Latic F, Kraljik D, Pitlovic V, Mrkovic H, Miskic D, et al. Treatment of common bile duct stones-is the role of ERCP changed in era of minimally invasive surgery? Med Arh 2010;64:187-8. doi: 10.5455/medarh.2011.65.371-372.

30. Kharbutli B, Velanovich V. Management of preoperatively suspected choledocholithiasis: A decision analysis. J Gastrointest Surg 2008;12:1973-80. doi: 10.1007/ s11605-008-0624-6.

31. Hormati A, Ghadir MR, Sarkeshikian SS, Modarres MP, Rafiei M, Alemi F. Efficacy of Common Bile Duct Stenting for Large Stones. Govaresh 2017;22:18-23. 